\title{
Modeling Financial Surplus of the Housing Projects Developer
}

\author{
Tadeusz Czernik¹, Daniel Iskra² \\ ${ }^{1}$ University of Economics in Katowice \\ Faculty of Finance and Insurance, Department of Applied Mathematics \\ Pułaskiego 25, 40-287 Katowice, Poland \\ tadeusz.czernik@ue.katowice.pl \\ ${ }^{2}$ University of Economics in Katowice \\ Faculty of Finance and Insurance, Department of Applied Mathematics \\ Pułaskiego 25, 40-287 Katowice, Poland \\ daniel.iskra@ue.katowice.pl
}

\begin{abstract}
Recent events taking place on the housing project market provide a strong impetus to the study of risk in housing project development. This issue is important not only from the point of view of the developer but also his client. This paper proposes a dynamic model of the financial surplus process. The model takes into account the structure of the credit payments, and the random nature of the real estate sale process (compound Poisson process: the moment of sale and sale price), predictable and unpredictable expenses. Monte Carlo simulations were performed in order to introduce this model. The purpose of this paper is to present the proposed model of financial surplus that can be a starting point for further research and analysis.
\end{abstract}

Keywords: housing projects development, financial surplus, stochastic modeling, simulations

JEL codes: C02, C63, G33, R30

\section{Introduction}

The events of recent years in the property development market have attested to the urgent necessity to carry out research on the risk associated with the development of housing investments (Tworek, 2010b). The topic of risk of construction investments is not only relevant from the point of view of developers but also of their customers. The literature on the risk of investments related to construction mostly covers the topic of risk arising from the contractor of the construction project (Skorupka, 2007), (Tworek, 2010a), (Huh et al, 2012). The problem of project scheduling with probabilistic cash inflows was discussed in e.g. (Ozdamar et al, 1997). This paper presents a dynamic model of a financial surplus of a property development company.

\section{Methodology}

For the purposes of this study the authors have assumed that the financial surplus is the balance of the current account of the company. Therefore, negative balance of the surplus will be interpreted as a working capital facility granted by 
the bank to the developer. In the study, the financial surplus is a random process $N(t)$ with the known initial value $N(0)=N_{0}$. The dynamics of the surplus is described using the following stochastic difference equation

$$
\Delta N=N_{k+1}-N_{k}=\sum_{i} P_{k+1, i}
$$

where

$N_{k}$ - financial surplus at time $k \in\{0,1, \ldots, T\}$

$T$ - simulation horizon (days)

$P_{k, i}$ - deterministic or random cashflow of the $i$ th factor at time $k$.

The time unit is one day, and one year comprises 360 days (no distinction between business days and holidays was made). Additionally, the initial point of the investment was not placed in a specified range within the calendar year.

The following cashflows were taken into account

- $\quad$ interest on current account - interest accrued each day (interest rate was not applied in case of positive surplus capital)

$$
P_{k+1,1}=I_{k+1}=N_{k}\left(\left(1+\frac{i^{(12)}}{12}\right)^{\frac{12}{360}}-1\right) \theta\left(-N_{k}\right)
$$

where: $i^{(12)}$ - nominal interest rate of the overdraft on the current account, $\theta(x)=\left\{\begin{array}{ll}0 & \text { dla } x \leq 0 \\ 1 & \text { dla } x>0\end{array}\right.$ - Heaviside step function

- $\quad$ standard aggregate costs of business activity $P_{k, 2}$ - salaries, cost of rental/maintenance of office space, marketing expenses etc. (tax-related aspects were ignored)

- investment loan $P_{k, 3}$ - tranches of the loan and installments

- costs related to the implementation of the investment $P_{k, 4}$

- revenue from the sale of residential premises $P_{k, 5}$

- $\quad$ other unexpected costs $P_{k, 6}$.

Tax-related aspects of the undertaking were ignored.

\subsection{Credit interest rate}

For the purposes of the simulations it was assumed that the process of spot rate (LIBOR ON) is generated by the equation [CIR] (all stochastic differential equations are understood in the sense of Ito (Oksendal, 2007), (Hanson, 2007)) 


$$
d r_{t}=\alpha\left(\mu-r_{t}\right) d t+\sigma \sqrt{r_{t}} d W_{t}
$$

where

$r_{t}$ - spot rate (LIBOR ON)

$W_{t}$ - Wiener process

$\alpha, \mu, \sigma>0$ - parameters.

The authors decided to employ CIR model because of its appealing characteristics:

- $\quad$ spot rate of zero (also negative) is precluded if the $\frac{2 \alpha \mu}{\sigma^{2}}>1$ is met

- $\quad$ CIR is an autoregressive mean-reverting model

- the formulas for the valuation of a zero-coupon bond have a simple form.

CIR model allows to analytically determine the price of a zero-coupon bond $P(t, T)$ with a face value equal to one monetary unit

$$
P(t, T)=A(t, T) e^{-B(t, T) r_{t}}
$$

where $A(t, \mathrm{~T})=\left(\frac{2 h e^{\frac{(\alpha+h)(T-t)}{2}}}{2 h+(\alpha+h)\left(e^{(T-t) h}-1\right)}\right)^{\frac{2 \alpha \mu}{\sigma^{2}}} \quad, \quad B(t, \mathrm{~T})=\frac{2\left(e^{(T-t) h}-1\right)}{2 h+(\alpha+h)\left(e^{(T-t) h}-1\right)}$, $h=\sqrt{\alpha^{2}+2 \sigma^{2}}$.

Since it was assumed for the purposes of the simulations that the borrowing rate is based on the rate of LIBOR EUR 3M (the beginning value of the borrowing rate ( WIBOR $3 M_{0}$ ) was converted to the spot rate $r_{0}$ using the following formula

$$
\left(1+\frac{{\text { LIBOR } 3 M_{0}}_{0}}{12}\right)^{-12 \square \frac{90}{360}}=A\left(0, \frac{90}{360}\right) e^{-B\left(0, \frac{90}{360}\right) r_{0}}
$$

where the values of the parameters $\alpha=0.5, \mu=0.003, \sigma=0.02$ were adopted on an ad hoc basis.

By solving the equation the following is obtained

$$
r_{0}=\frac{1}{B\left(0, \frac{90}{360}\right)} \ln \left(\frac{\left(1+\frac{{\text { IIBOR } 3 M_{0}}_{0}}{12}\right)^{12 \frac{90}{360}}}{A\left(0, \frac{90}{360}\right)}\right) \text {. }
$$


The values of LIBOR 3M are determined using the formula

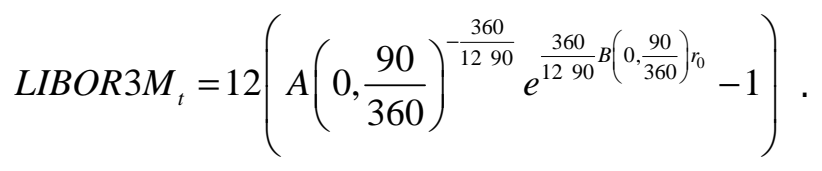

The simulations assumed that the bank updates the borrowing rate every three months based on the current value of LIBOR 3M or based on the averaged values LIBOR $3 \mathrm{M}$ from the past few days. For the purposes of the simulation a principle was assumed based on the averaged LIBOR 3M from the last 5 quotes.

Figure 1 shows sample LIBOR3M realizations, initial value of $\operatorname{LIBOR} \mathrm{M}_{0}=0.3 \%$.

Figure 1 Sample three LIBOR3M realizations

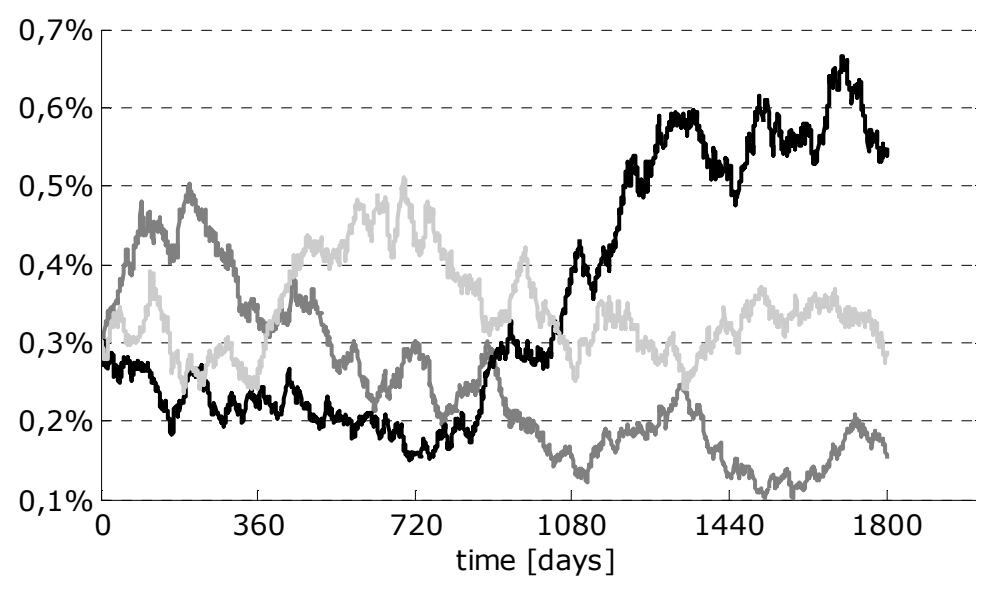

Source: own elaboration

Some banks change the borrowing rate only where the change in the value of LIBOR 3M (or its average) is greater than the previously set value (the formula for an update based on LIBOR $3 \mathrm{M}$ for a given day)

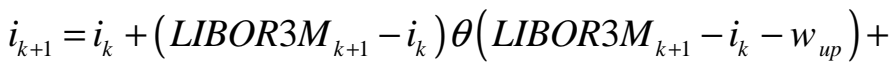

$$
\begin{aligned}
& +\left(\operatorname{LIBOR}_{3} M_{k+1}-i_{k}\right) \theta\left(i_{k}-\operatorname{LIBOR} 3 M_{k+1}-w_{\text {down }}\right)
\end{aligned}
$$

where

$i_{k}$ - borrowing rate

$w_{u p}, w_{\text {down }}$ - minimum value of the increase/decrease of LIBOR 3M resulting in a change of the borrowing rate. In general $w_{u p} \neq w_{\text {down }}$.

The following figures show sample implementations of the borrowing rate (excluding margin), without and with changes' thresholds. For the purposes of the 
simulations the beginning value $\operatorname{LIBOR} 3 M_{0}=0.3 \%$ was assumed, and $w_{u p}=0.0002, w_{\text {down }}=0.0004$. This asymmetric selection of the thresholds is advantageous to the bank because the bank will raise the borrowing rate, if LIBOR 3M exceeds the borrowing rate for the previous period $i_{k}$ by at least 0.0002 . The bank will lower the borrowing rate, if LIBOR $3 M$ is lower than the current rate $i_{k}$ by at least 0.0004 . Therefore, the increase of the rate is more likely than its decrease.

Figure 2 Sample credit interest rate realizations without thresholds

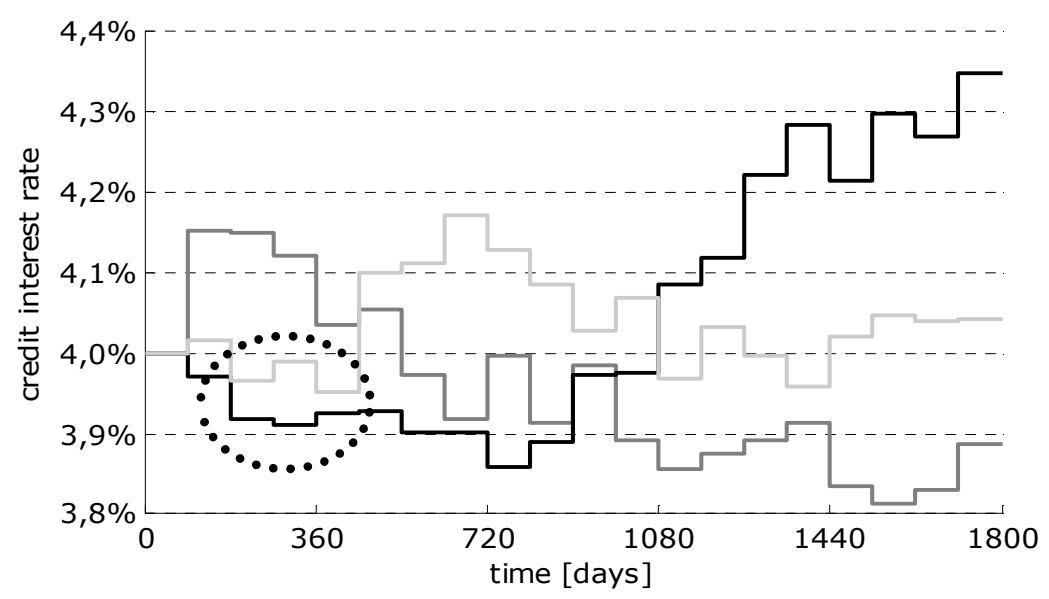

Source: own elaboration

Figure 3 Sample credit interest rate realizations with thresholds

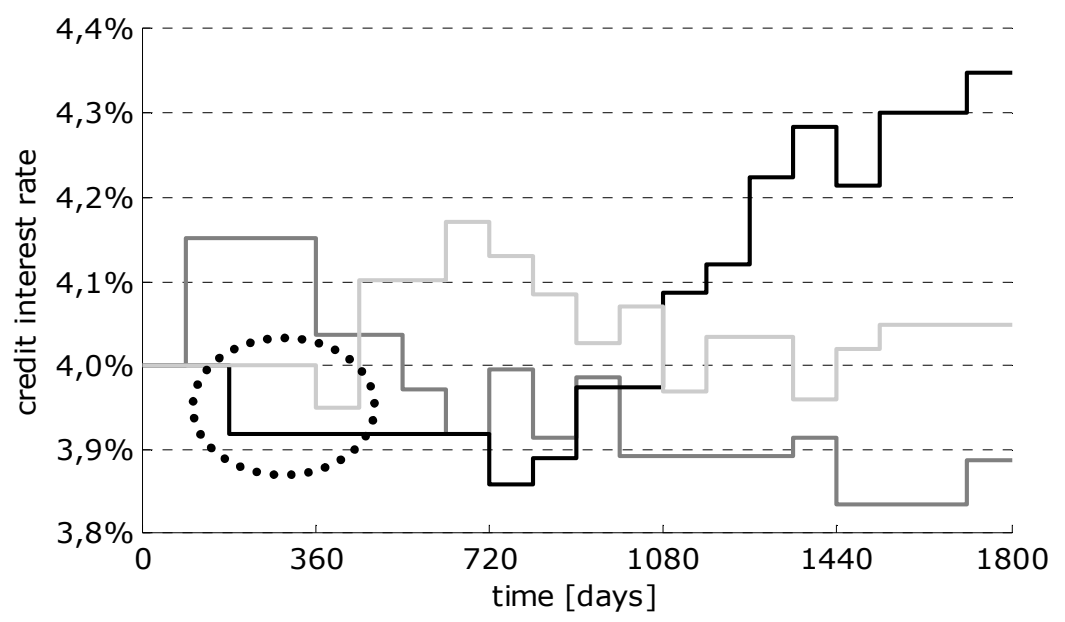

Source: own elaboration 
As shown above, after application of the threshold credit rate, the realizations become more stable (compare circle interior).

\subsection{Selling process}

Three types of residential premises were considered for the purposes of the simulations. In general, it is possible to consider any number of the premise classes. The process of the amount of the sold premises within each of the three classes $n_{i, t}(i=1,2,3)$ is modeled using independent non-homogenous Poisson processes

- $n_{i, 0}=0$

- independent increments

- $\quad$ if $\Delta t \square 1$ then $P\left(n_{i, t+\Delta t}-n_{i, t}=1\right)=\lambda_{i, t} \Delta t+o(\Delta t)$

- $\quad$ if $\Delta t \square 1$ then $P\left(n_{i, t+\Delta t}-n_{i, t}>1\right)=o(\Delta t)$

where $\lambda_{i, t} \geq 0$ is the intensity of the sale process at time $t$.

It can be demonstrated that the probability of the sale of $k$ premises of class $i$ during time period $(t, t+\Delta t)$ can be expressed as

$$
P\left(n_{i, t+\Delta t}-n_{i, t}=k\right)=\frac{m_{i}(t, \Delta t)^{k}}{k !} e^{-m_{i}(t, \Delta t)}
$$

where $m_{i}(t, \Delta t)=\int_{t}^{t+\Delta t} \lambda_{i, s} d s$

The intensity of the sales process was modeled based on the shifted gamma distribution (shifted gamma distribution is obtained by excluding the $K_{i}$ constant)

$$
\lambda_{i, t}=K_{i} \frac{b_{i}^{a_{i}}}{\Gamma\left(a_{i}\right)}\left(t-t_{i, \mathrm{start}}\right)^{a_{i}-1} e^{-b_{i}\left(t-t_{i, \text { sart }}\right)} \theta\left(t-t_{i, \mathrm{start}}\right)
$$

where

$K_{i}>0$ - proportionality constant, $a_{i}, b_{i}>0$ parameters, $\Gamma\left(a_{i}\right)=\int_{0}^{+\infty} z^{a_{i}-1} e^{-z} d z-$ gamma function and $t_{i, \text { start }}$ - start time of selling class $i$ premises.

The intensity of the sales is at its peak at the time 


$$
t_{i, \max }=\frac{a_{i}-1}{b_{i}}+t_{i, \mathrm{start}} \quad \text { for } \quad a_{i}>1
$$

In the simulations authors assumed that

$$
\begin{aligned}
& t_{1, \text { start }}=t_{2, \text { start }}=t_{3, \text { start }}=t_{\text {start }} \\
& t_{1, \max }=t_{2, \max }=t_{3, \max }=t_{\text {max }} .
\end{aligned}
$$

On the basis of (11), (12), (13) it is possible to express $a_{i}$ by $b_{i}$

$$
a_{i}=\left(t_{\max }-t_{\text {start }}\right) b_{i}+1>1 \text {. }
$$

In the simulations it was also assumed that the most likely amount of sold premises within the analyzed time frame $t_{k}$ is equal to the total number of built premises $l_{i}$

$$
K_{i} \frac{\gamma\left(\left(t_{\max }-t_{\text {start }}\right) b_{i}+1, b_{i}\left(t_{k}-t_{\text {start }}\right)\right)}{\Gamma\left(\left(t_{\max }-t_{\text {start }}\right) b_{i}+1\right)}=l_{i}
$$

where $\gamma(x, y)=\int_{0}^{y} z^{x-1} e^{-z} d z$ is the incomplete gamma function.

To determine the value of $b_{i}$ it was assumed that the most likely percentage of sold premises in class $i$ until time $t_{q i}$ is $q_{i}$

$$
\frac{\gamma\left(\left(t_{\max }-t_{\text {start }}\right) b_{i}+1, b_{i}\left(t_{q i}-t_{\text {start }}\right)\right)}{\gamma\left(\left(t_{\max }-t_{\text {start }}\right) b_{i}+1, b_{i}\left(t_{\max }-t_{\text {start }}\right)\right)}=q_{i}
$$

The parameter $b_{i}$ is the solution of the equation (16), which has no analytical solutions, therefore it was necessary to apply a numerical algorithm.

Figure 4 shows the sales' intensity $\lambda_{, t}$ (for $q_{1}=0.4, q_{2}=0.6, q_{3}=0.5$ and $t_{q 1}=800, t_{q 2}=900, t_{q 3}=850$ days $)$. 
Figure 4 The intensity of the sales process

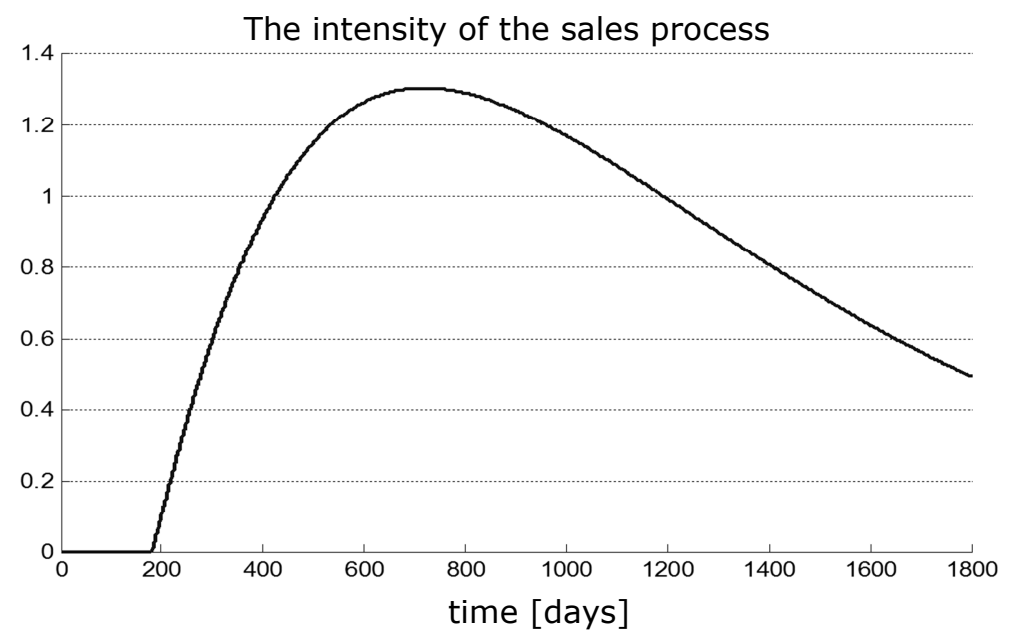

Source: own elaboration

The presented algorithm generates only the sale process of the premises. The algorithm presented below allows inclusion of the price negotiations.

Transaction prices of a square meter for each of the classes are within the following ranges

$$
\begin{aligned}
& C_{1} \in\left[k_{1} C_{\text {min }}, k_{1} C_{\text {max }}\right] \\
& C_{2} \in\left[k_{2} C_{\text {min }}, k_{2} C_{\text {max }}\right] \\
& C_{3} \in\left[k_{3} C_{\text {min }}, k_{3} C_{\text {max }}\right]
\end{aligned}
$$

where

$C_{i}$ - price of a square meter in class $i$

$k_{i}$ - multiplier for class $i$

$C_{\min }, C_{\max }$ - respectively the minimum and maximum base price.

The minimum base price was determined on the basis of an initial simulation so that there is probability $p_{1}$ that the final financial surplus is greater than zero. Price $C_{\max }$ was set so that there is probability $p_{2}$ that the final surplus is greater than the initial surplus subject to a set interest rate (i.e. deposit interest rate).

Transaction prices $C_{i}$ were generated basing on a transformed beta distribution

$$
C_{i}=k_{i}\left[C_{\min }+\left(C_{\max }-C_{\min }\right) Y\right]
$$


where $Y$ is a random variable with a beta distribution (Gentle, 2003) $f_{Y}(y)=\frac{1}{B\left(\alpha_{i}, \beta_{i}\right)} y^{\alpha_{i}-1}(1-y)^{\beta_{i}-1}$ and $B\left(\alpha_{i}, \beta_{i}\right)=\frac{\Gamma\left(\alpha_{i}\right) \Gamma\left(\beta_{i}\right)}{\Gamma\left(\alpha_{i}+\beta_{i}\right)}$ is a beta function.

From the point of view of the above considerations on the sale process of premises and the transaction prices, the selling process is a compounded Poisson process.

\section{Results}

It was assumed for the purposes of the simulations that the time unit is one day and one year comprises 360 days (no distinction between business days and holidays was made). The beginning value of the surplus is $N(0)=€ 0.5$ million, the planned total cost of the investment amounts to $€ 5$ million (construction cost of $€ 4.5$ million plus other costs: marketing, etc.).

The missing capital is borrowed. For the purposes of the simulations it was assumed that the repayment period of the loan is five years and the time of payment of the loan is the time of the settlement of the investment (the loan is not repaid in advance). A loan in the amount of $€ 4.5$ million was awarded in three tranches. The first tranche is paid at the beginning of the investment and the next ones at the end of the following half-years (the tranches were set to amount to $€ 0.6, € 2.6, € 1.8$ million). The borrowing rate consisted of a fixed $3.7 \%$ margin plus LIBOR 3M (generated by the respective process). The simulations assumed that the repayment of the loan is deferred for one year, and during the deferment period the debt accumulated in accordance with the assumed borrowing rate for the given period (monthly compounding in arrears). The first non-zero installment is repaid after a year. Together with the update of the debt to include a new tranche the entire loan repayment plan was updated. As noted earlier, any other costs associated with the loan, such as the commission or insurance, were ignored.

The estimated cost of the construction amounting to $€ 4.5$ million was spread over two years (the expected date of completion of the construction). Some costs were covered on a monthly basis in the amount of $€ 100,000$ and the remaining amount was paid in 4 tranches of $€ 525,000$ at the end of each half-year. Additionally two costs of unpredicted amounts associated with the construction were generated, each up to $5 \%$ of $€ 4.5$ million, at randomly generated times between month 6 and 25 of the investment.

Standard aggregate costs of business activity (salaries, cost of rental/maintenance of office space, marketing expenses etc) were assumed to amount to $€ 100,000$ plus up to (generated randomly) $10 \%$ of $€ 100,000$. 
The process of selling the premises begins 6 months after the commencement of the investment, the sale of the premises is identified with financial flow payment. Three types of residential premises were considered for the purposes of the simulations

- 100 premises with an area of $50 \mathrm{~m} 2$

- 50 premises with an area of $80 \mathrm{~m} 2$

- 25 premises with an area of $120 \mathrm{~m} 2$

The maximum intensity of the sale was assumed to occur after two years from the beginning of the investment (planned completion time), whereas it was assumed that a period of five years (the entire term of the investment) is the period in which the most probable number of sold premises is $100 \%$ (this does not mean, however, that all premises will be sold at that time),

Transaction prices are generated randomly within a set range. For each class the price range of the premises are adjusted using the appropriate multiplier ( $k_{1}=1, k_{2}=1.1, k_{3}=1.3$ ). The initial price range is adjusted based on a measure referred to as the probability of failure to achieve the aspiration level. The minimum price was determined so that the probability of the event that the generated final surplus in pre-simulations (50 000) will have a value less (or equal to) zero and will not exceed 0.1 . The maximum price was generated in a similar manner (for a probability of 0.01), whereas the aspiration level was then set as the value of the initial surplus value subject to the demanded rate of return (assumed at the level of $10 \%$ p.a.) for the entire period of the investment. After the determination of the initial price range, subsequent simulations of the implementation of the surplus were carried out, in which the price of the premises (expressed per $\mathrm{m}^{2}$ ) was generated on the basis of the previously determined range.

The interest rate on the current account with the surplus (the interest compounded on a daily basis) was $15 \%$ for an overdraft, interest rate was not applied in case of positive surplus capital (that is, for positive values of $N(t)$ the interest rate was assumed to be $0 \%$ ).

With the above assumptions, Monte Carlo simulations were carried out by generating 50000 realizations of daily changes in surplus capital both in the presimulations (establishment of the initial price range per $\mathrm{m}^{2}$ ) and in the final simulations. The minimum price in the pre-simulations was obtained at $€ 1100$ per $\mathrm{m}^{2}$, the maximum price: $€ 1400$ per $\mathrm{m}^{2}$.

Figure 5 presents examples of financial surplus realization. First credit tranche $€ 500000$ is paid at time zero, hence initial amount of money is $€ 1000000$. 
Figure 5 Sample of financial surplus realizations

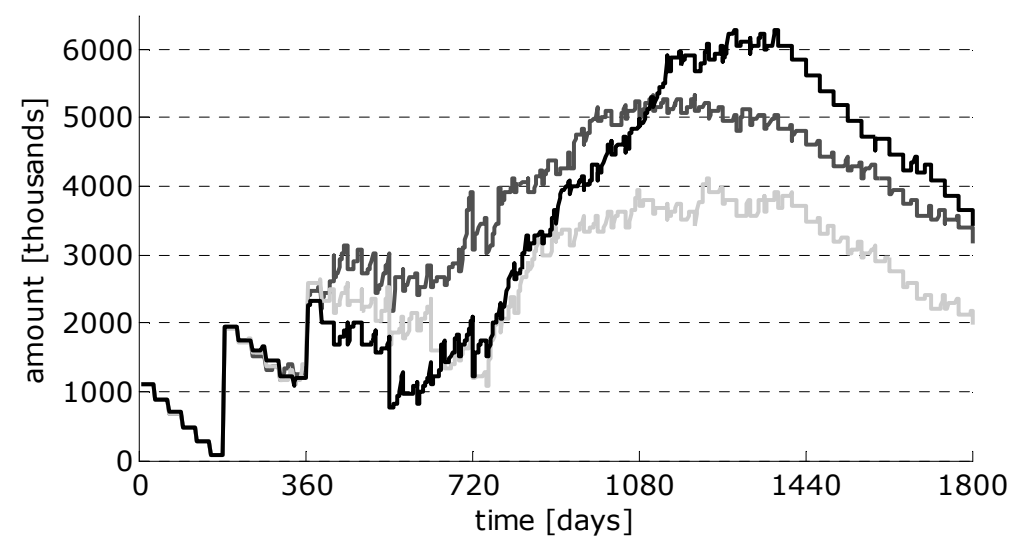

Source: own elaboration

As one can see in the picture, surplus capital decreases at the start of sales. There are only minor differences between trajectories caused by the stochastic nature of the credit rate (small diffusion intensity). The sale process starts to differentiate stochastic trajectories. During the first year of the sale process, selling intensity is small and increases.

In Figure 6 we can see the probability density functions of financial surplus. As explained above, the dispersion of financial surplus after one year should be small (see Figure 6). After the selling process starts, the dispersion increases.

Figure 6 PDFs of financial surplus
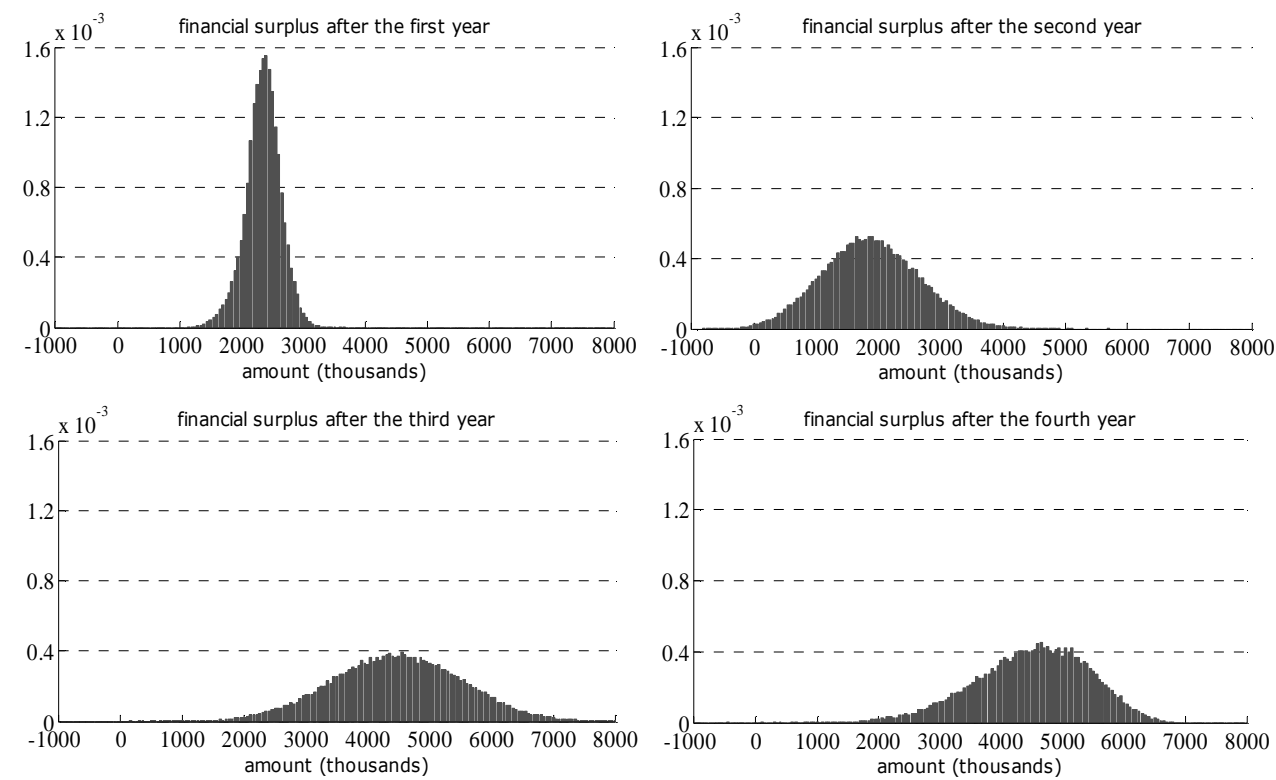

Source: own elaboration 
A histogram of the final surplus (that is, the surplus after five years of the investment, regardless of whether all the apartments will have been sold) is shown below. The histogram shows that the settlement of the investment may result in losses, in extreme cases even up to $€ 0.5$ million. Therefore, it should be considered whether it is reasonable to initiate a procedure of early withdrawal from the investment and minimizing losses. However, in the vast majority of cases the final surplus is positive and greater than the initial value (the average value of the financial surplus after the fifth year of the investment amounts to $€ 3.4$ million). The average number of premises which haven't been sold is approximately 8 .

Figure 7 Histogram of final financial surplus

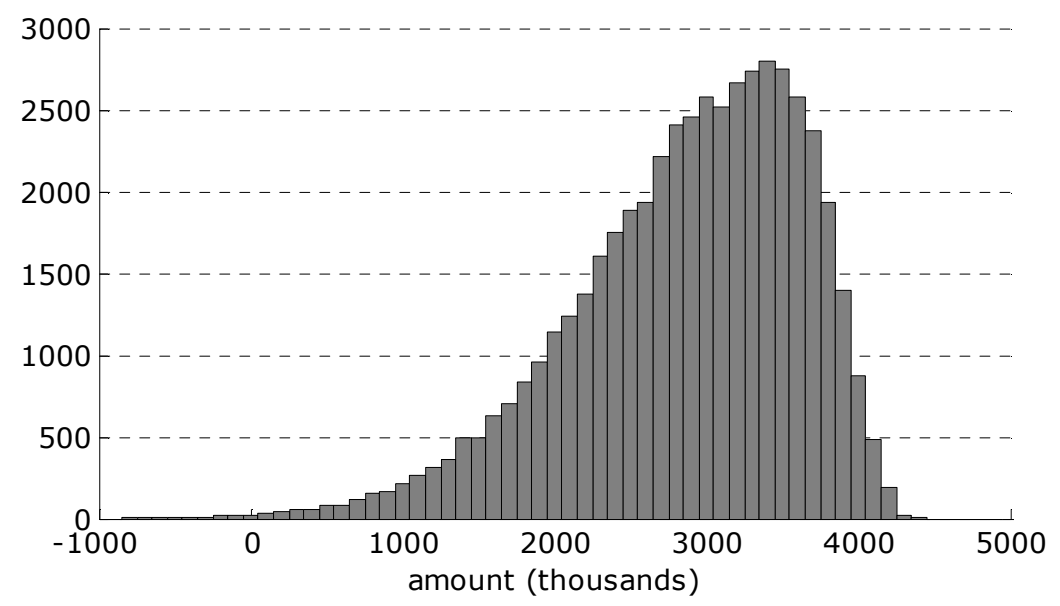

Source: own elaboration

Figure 8 shows the surplus confidence interval. One can observe that dispersion initially increases and after approximately 40 months decreases. This is because it is likely that by that time most of the apartments were sold, the process of loan repayment begins to dominate.

Figure 9 shows the quantile of the final financial surplus for probability levels of $0.01,0.03$, and 0.05 . The quantile determined on the basis of the empirical distribution of the final surplus amounts to: $€ 1,3$ million, $€ 1.7$ million and $€ 2.0$ million, for the respective assumed tolerance levels. The corresponding Value at Risk (Alexander, 2008), (Iskra, 2011) figure would be analogous. 
Figure 8 Confidence interval

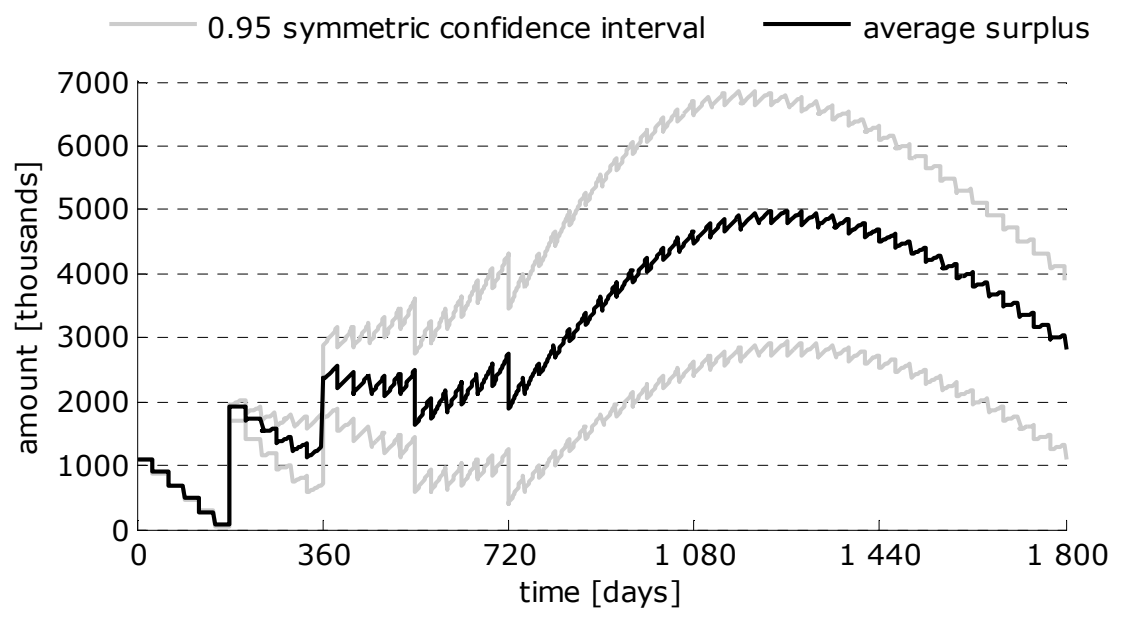

Source: own elaboration

Figure 9 Quantile of financial surplus

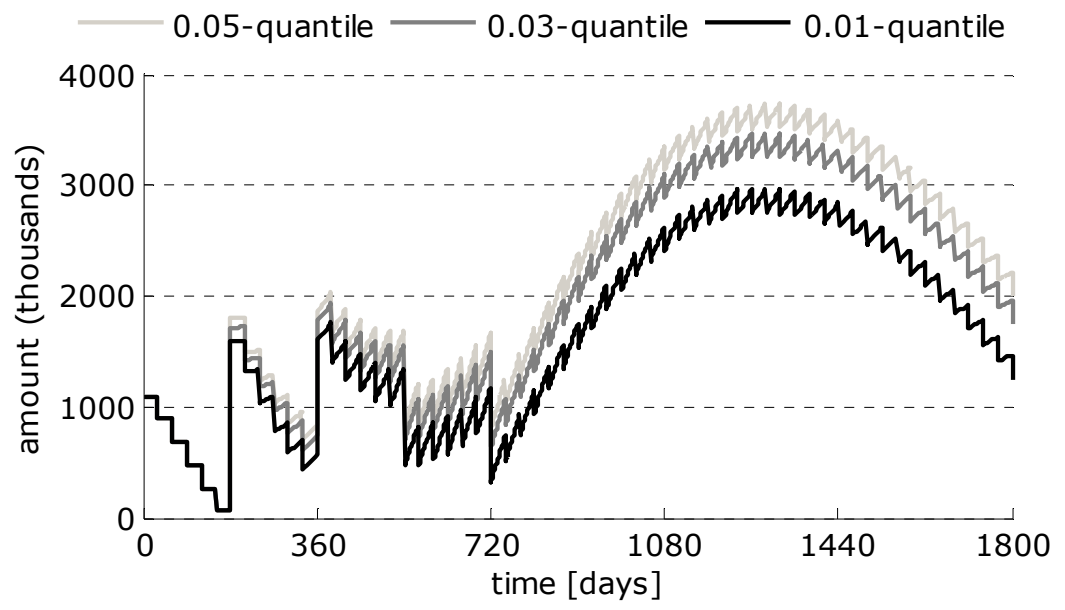

Source: own elaboration

\subsection{Occupation time and stress testing}

A stress test, in financial terminology, is an analysis or simulation designed to determine the ability of a given financial system or financial institution to deal with an economic crisis. In the proposed economic system we will test sensitivity of financial surplus to changes in the intensity of sales. One can also analyze sensitivity of apartment price decrease and the increase in credit rate. We conduct a sensitivity analysis using relative occupation time (ROT) as a risk measure. We propose to use ROT due to the higher chance of bankruptcy 
resulting from the increased time duration through which the surplus remained below zero.

Occupation time $O T_{t}(A)$ of the process $X_{t}$ is defined as follows (Bayraktar and Young, 2010), (Cai et al. 2010):

$$
O T_{t}(A)=\int_{0}^{t} 1_{A_{s}}\left(X_{s}\right) d s
$$

where:

$A_{t}$ - domain (subscript $t$ denotes dependence on time - deterministic or stochastic),

$1_{A_{t}}\left(X_{t}\right)=\left\{\begin{array}{ll}1 & X_{t} \in A_{t} \\ 0 & X_{t} \notin A_{t}\end{array}\right.$ - indicator function.

By definition, the occupation time is a random process.

Figures 10 present a sample trajectory of the process $X_{t}$ and its occupation time process in the following domains $A=[0.2,+\infty)$.

Figure 10 Occupation time for sample process $X_{t}$ and $A=[0.2, \infty)$

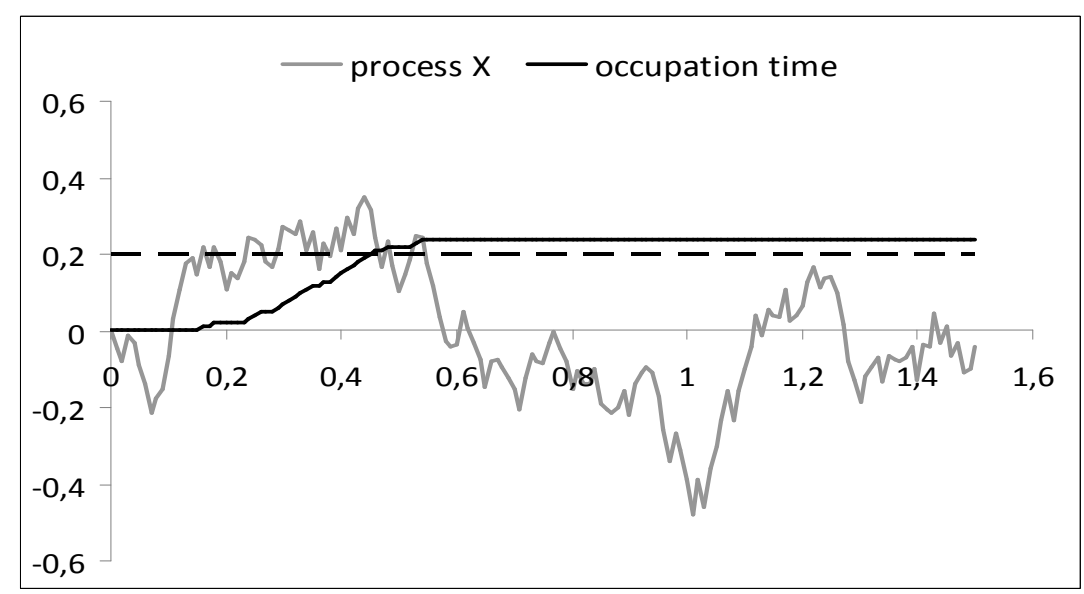

Source: own elaboration

Other quantity associated with occupation time is the relative occupation time $\operatorname{ROT}_{t}(A)$ (Czernik, 2013): 


$$
\operatorname{ROT}_{t}(A)=\frac{1}{t} O T_{t}(A)=\frac{1}{t} \int_{0}^{t} 1_{A_{s}}\left(X_{s}\right) d s
$$

Figure 11 shows histograms of the relative occupation time. $\operatorname{ROT}_{t}(A)$ of the surplus process is determined empirically for $A=(-\infty, 0)$, where the selling intensity were not reduced and with reduction by $10 \%, 30 \%$ and $50 \%$.

In the scenario without reduction and with a probability of approximately 0.996 , the financial surplus is always positive. If we reduce the intensity by $10 \%$ probability of the event $R O T>0$ decreases to app. 0.964 . In case of reduction by $30 \%$ and $50 \%$, the probability mentioned above decreases to about 0.25 and zero respectively.

Figure 11 Histogram of relative occupation time $(A=(-\infty, 0))$
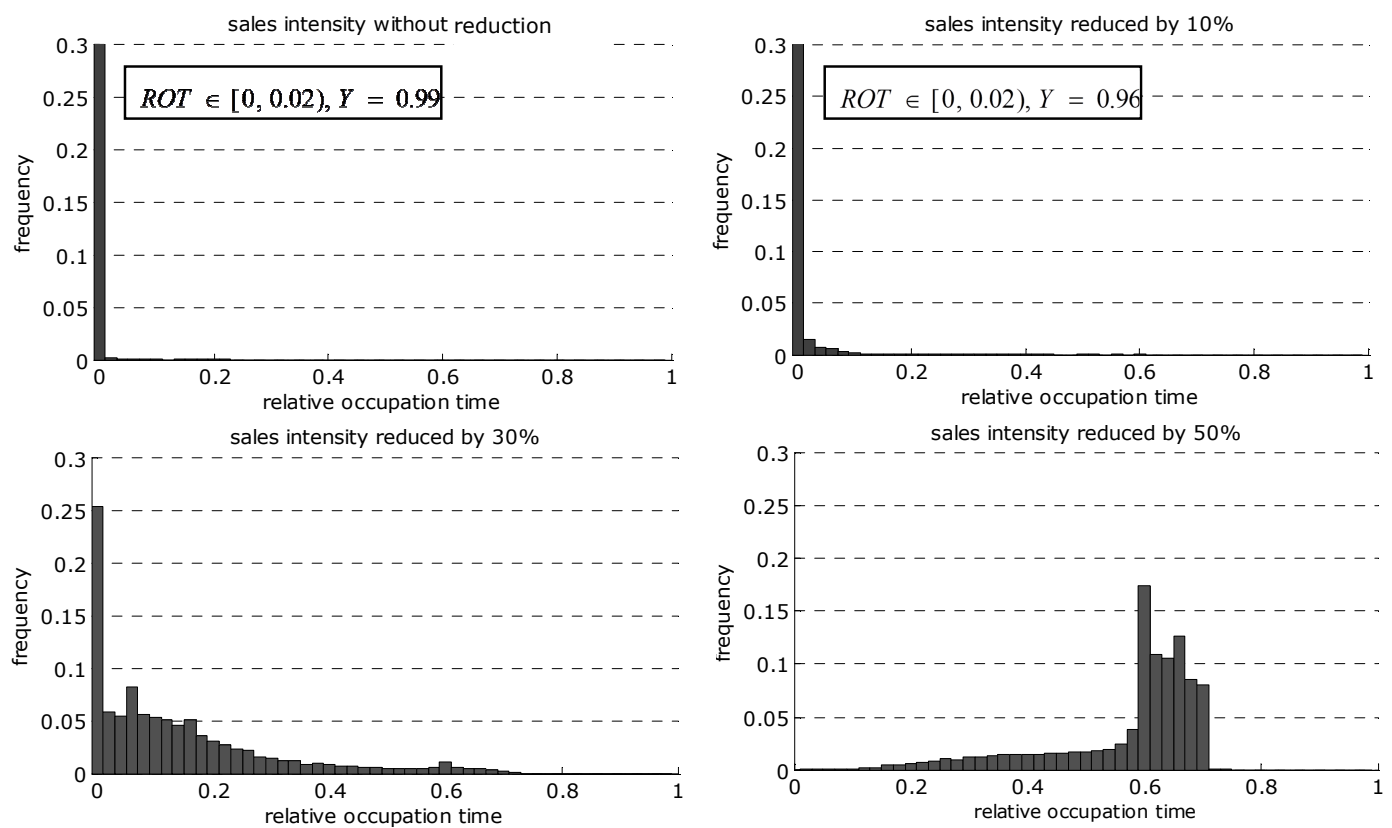

Source: own elaboration

Average ROTs obtained from simulation are $0.0001,0.002,0.137$ and 0.572 , respectively. As can be seen, the financial surplus is very sensitive to a decrease in selling intensity. Similar conclusions can be made by observing Figure 12.

Figure 12 shows the average values and 95\% symmetric confidence intervals of financial surplus (calculated for each day). 
Figure 12 Average values and 95\% symmetric confidence intervals
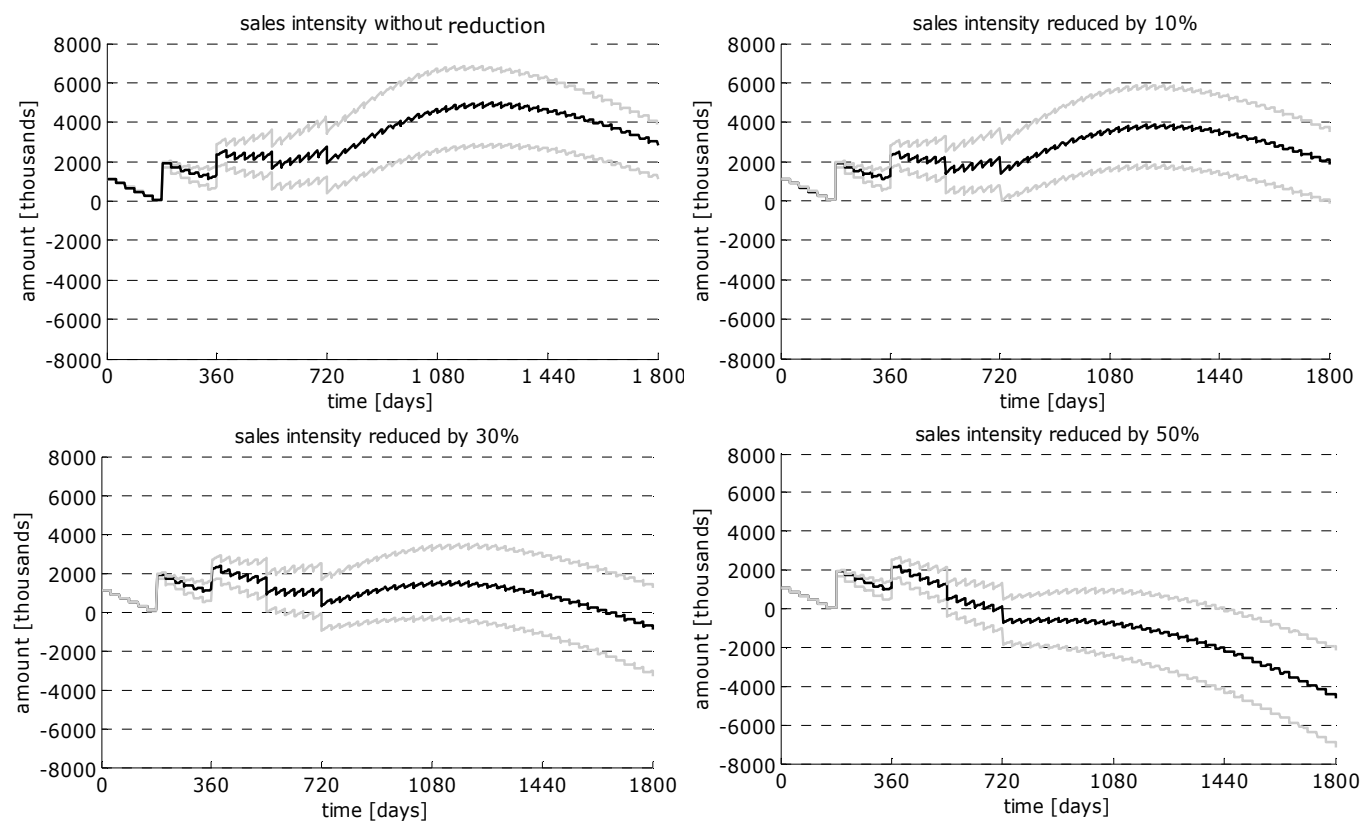

Source: own elaboration

In the case of reducing the intensity of sales by $50 \%$, the final value of the surplus will almost certainly be negative.

\section{Conclusions}

The model of the financial surplus presented in this paper is only a starting point for further considerations. As noted above, it ignores the relationships between the quantities, does not allow for calibration on the basis of the market data (process of the value of the sold premises, process of borrowing rates, pricedemand relationship), does not take into account the tax aspects of the investment and the possibility of the initiation of bankruptcy proceedings. Neither does it allow for the adjustment on the basis of the market data (process of the value of the sold premises, process of borrowing rates, price-demand relationship).

For this reason, further analyses should take into account the calibration of the model, possible decisions of the developer in the course of the investment (additional loans, lowering the price below the assumed minimum level to avoid insolvency, or the possibility of declaring insolvency). Additionally, the possibility of implementing different models of borrowing rate should be considered, as well as different models of the distribution of transaction prices or functional relationships of the intensity of the selling process. Measures of 
risk/attractiveness that augment the decision making with regard to the attractiveness of the investment can also be employed.

\section{References}

Alexander, C. (2008). Market Risk Analysis: Value at Risk Models, 4th ed. England: John Wiley \& Sons.

Bayraktar, E., Young, V. R. (2010). Optimal investment strategy to minimize occupation time. Annals of Operations Research, vol. 176(1), pp. 389-408.

Cai, N., Chen, N., Wan, X. (2010). Occupation Times of Jump-Diffusion Processes with Double Exponential Jumps and the Pricing of Options. Mathematics of Operations Research, vol. 35(2), pp. 412-437.

Czernik, T. (2013). Occupation time - potential applications. Geometric Brownian Motion case. In: Barczak, A. S., Tworek, P. (eds.), Zastosowanie metod ilościowych w zarządzaniu ryzykiem $w$ działalności inwestycyjnej. Katowice: Polish Economic Society.

Gentle, J. E. (2003). Random number generation and Monte Carlo methods. New York: Springer.

Hanson, F. B. (2007). Applied Stochastic processes and control for jumpdiffusions. Modeling, analysis, and computation. Philadelphia: SIAM.

Huh, Y. K., Hwang, B. G., Lee, J. S. (2012). Feasibility analysis model for developer-proposed housing projects in the republic of Korea. Journal of Civil Engineering and Management, vol. 18(3), pp. 345-355.

Iskra, D. (2011). Value at Risk - securities of portfolio optimization. A Geometric Brownian Motion case. Supplemento ai Rendiconti del Circolo matemattico di Palermo, vol. 2(83), pp. 199-208.

Oksendal, B. (2007). Stochastic Differential Equations: An Introduction with Applications. Berlin Heidelberg: Springer.

Ozdamar, L., Dundar, H. (1997). A flexible heuristic for a multi-mode capital constrained project scheduling problem with probabilistic cash inflows. Computers \& Operations Research, vol. 24(12), pp. 1187-1200.

Skorupka, D. (2007). Metoda identyfikacji i oceny ryzyka realizacji przedsięwzięć budowlanych. Warszawa: Wyd. Wojskowej Akademii Technicznej.

Tworek, P. (2010a). Methods of risk identification in companies' investment projects. In: Dluhosova, D. (ed.), Managing and modelling of financial risk. Ostrava, pp. 418-427.

Tworek, P. (2010b). Risk management standards - the review of approaches and concept. In: Dluhosova, D. (ed.), Managing and modelling of financial risk. Ostrava, pp. 409-417. 